Jędrzej ŁAMACZ1

Opiekun naukowy: Ireneusz WRÓBEL ${ }^{2}$

DOI: https://doi.org/10.53052/9788366249837.15

\title{
SYMULACJA PROCESU WTRYSKU TWORZYWA SZTUCZNEGO DO FORMY Z WYKORZYSTANIEM PROGRAMU MOLDEX
}

\begin{abstract}
Streszczenie: Przedmiotem pracy było przeprowadzenie symulacji procesu wtrysku tworzywa sztucznego do formy wtryskowej oraz porównanie wyników symulacji z rezultatem przeprowadzonych prób formy wtryskowej. Porównano wady wyprasek uzyskanych na drodze symulacji i w wyniku rzeczywistej próby. Narzędzie będące obiektem badań to forma wtryskowa zimnokanałowa, dwukrotna z ruchomymi elementami formującymi.
\end{abstract}

Słowa kluczowe: symulacja MES, wtrysk tworzywa sztucznego, formy wtryskowe,

\section{SIMULATION OF THE PLASTIC INJECTION PROCESS INTO THE MOLD}

Summary: The subject of the research was to simulate the process of plastic injection into the injection mold and to compare the simulation results with the results of the tests of the injection mold in the form of moldings on the basis of their defects. The examples that is the subject of the research is a double cold-channel injection mold with forming elements in the form of sliders.

Keywords: FEM simulation, plastic injection, injection molds

\section{Wstęp}

Technologia formowania wtryskowego to jeden $\mathrm{z}$ procesów przetwórstwa tworzyw sztucznych. Bierze w nim udział wtryskarka, forma wtryskowa i tworzywo będące tutaj materiałem wejściowym w postaci granulatu bądź krajanki, która trafia do leja zasypowego a następnie do cylindra wtryskarki. Cylinder jest ogrzewany zespołem grzałek, wewnątrz cylindra znajduje się ślimak. Uplastycznione tworzywo zostaje wprowadzone do formy gdzie następuje jego zestalenie. Następnie jest ono $\mathrm{w}$ postaci wypraski usuwane $\mathrm{z}$ formy wtryskowej.

\footnotetext{
1 Akademia Techniczno-Humanistyczna w Bielsku-Białej, Wydział Budowy Maszyn i Informatyki, specjalność: CAD/CAM , email : lamacz.jedrzej@gmail.com

${ }^{2}$ dr hab. inż., prof. ATH, Akademia Techniczno-Humanistyczna w Bielsku-Białej, Wydział Budowy Maszyn i Informatyki, email iwrobel@ath.bielsko.pl
} 
Wtryskiwanie jest procesem cyklicznym, składającym się z następujących etapów:

- zamykania formy wtryskowej,

- dosunięcia układu uplastyczniającego, tak aby dysza wtryskowa wtryskarki zetknęła się z tuleją wtryskową znajdującą się w formie,

- wtrysku - wprowadzenia uplastycznionego tworzywa i wypełnienia gniazda formującego,

- fazy docisku - polegającej na uzupełnieniu tworzywa w gnieździe formującym po zmniejszeniu jego objętości spowodowanym skurczem tworzywa,

- chłodzenia wypraski w formie oraz jednoczesnego pobrania tworzywa z leja zasypowego oraz jego uplastycznienia,

- odsunięcia układu uplastyczniającego od tulei wtryskowej w formie oraz jednoczesnego otwarcia formy i usunięcia wypraski przy pomocy układu wypychania,

- kolejny cykl rozpoczyna się ponownego od zamknięcia formy wtryskowej.

\section{Forma wtryskowa}

Tak złożone narzędzie jakim jest forma wtryskowa musi spełnić wiele wymagań. Jej podstawową funkcją jest umożliwienie wypełnienia gniazda formującego uplastycznionym tworzywem przez układ zasilania wtryskarki i uformowanie wyrobu, który odzwierciedla kształt gniazd formujących. Kolejną jej funkcją jest odprowadzanie ciepła od płynnego tworzywa w sposób efektywny i równomierny. Trzecią podstawową funkcją jest zapewnienie możliwości szybkiego usuwania wypraski $\mathrm{z}$ formy $\mathrm{w}$ powtarzalny sposób. Szczegółowy schemat budowy przykładowej formy wtryskowej został przedstawiony na rysunku 1.

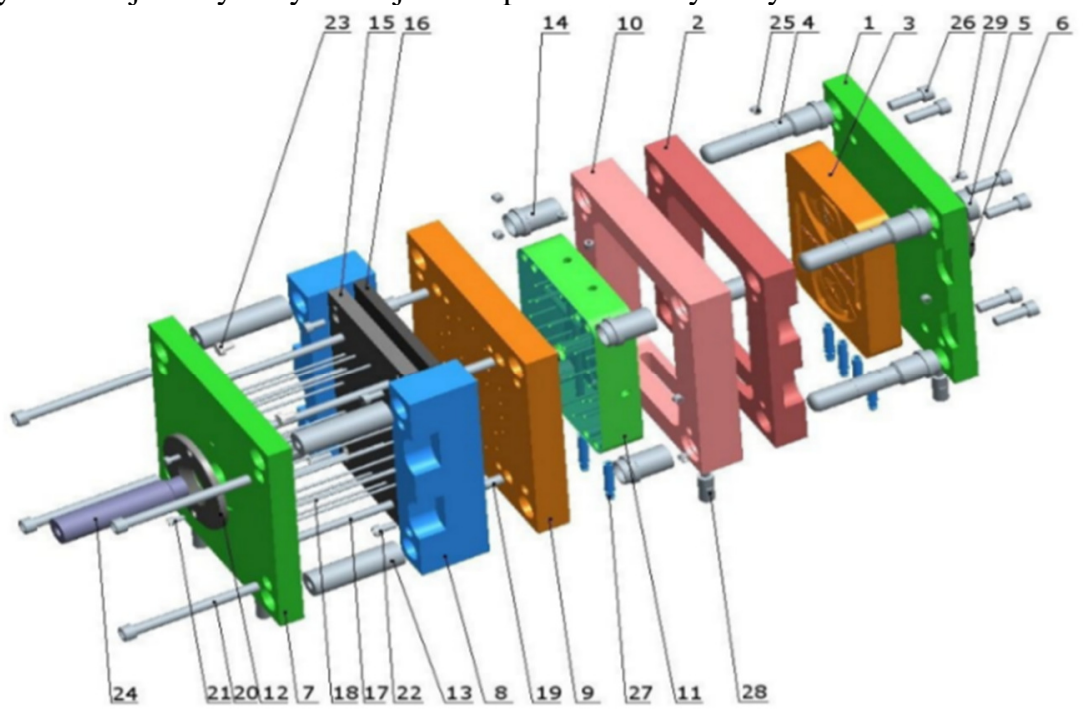

Rysunek 1. Schemat budowy formy wtryskowej [5]

W formie wtryskowej wyróżnia się kilka układów funkcjonalnych, są nimi: 

a) gniazdo formujące,
b) układ wlewowy,
c) układ chłodzenia,
d) układ wypychania wypraski,
e) układ usuwania wlewka,
f) obudowa wraz z elementami ustalającymi i prowadzącymi.

\section{Symulacja procesu i wyniki analiz}

Zarówno wypraskę jak i formę wtryskową zaprojektowano w oprogramowaniu Solidworks. Wypraska była wykonana z polipropylenu Moplen EP300 K. Symulację przeprowadzono w oprogramowaniu Moldex 3D. Założono następujące parametry procesu:

- maksymalne ciśnienie wtrysku: $P_{w}=66,7 \mathrm{MPa}$,

- maksymalne ciśnienie docisku: $P_{d}=77,7 \mathrm{MPa}$,

- $\quad$ czas wtrysku: $t_{w}=5 \mathrm{~s}$,

- $\quad$ czas docisku: $t_{d}=4 s$,

- temperatura tworzywa na czole ślimaka: $T_{w}=190^{\circ} \mathrm{C}$,

- temperatura formy wtryskowej: $T_{f}=35^{\circ} \mathrm{C}$.

Na rysunku 2 przedstawiono model wypraski jaka była poddana analizie.

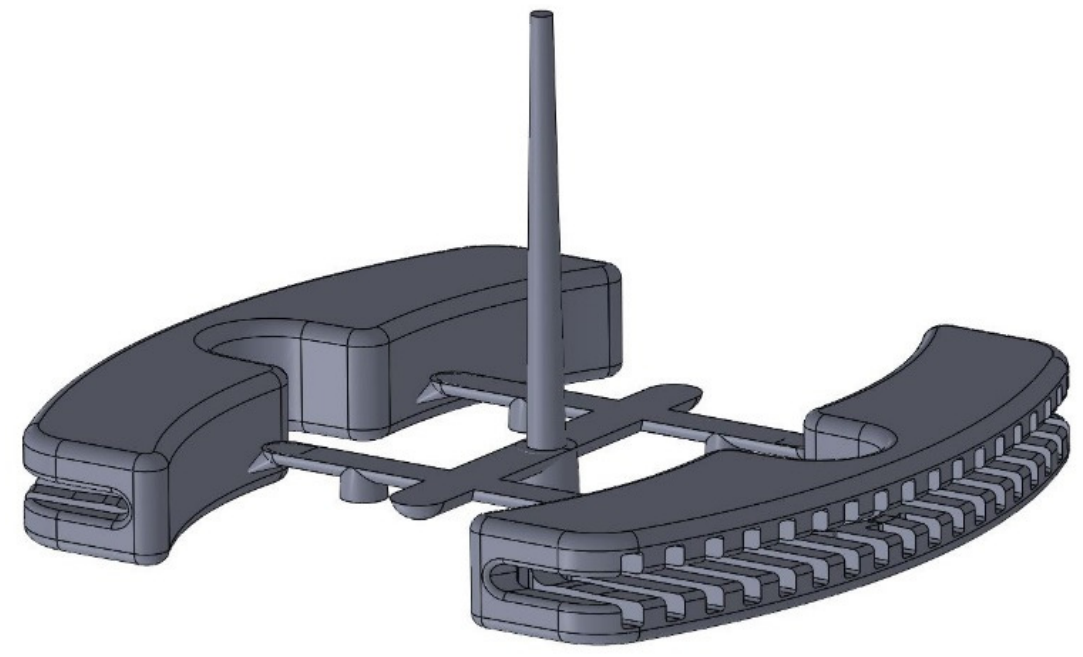

Rysunek 2. Model wypraski wraz z kanatem wlewowym

Wyniki symulacji porównano $\mathrm{z}$ rezultatem przeprowadzonych prób formy wtryskowej. Zbieżność wyników symulacji z wynikami oględzin wyprasek oceniano na podstawie ich wad. Wypraska będąca obiektem badań to uchwyt do wiadra budowlanego. 


\section{1. Ślady łączenia się strumieni uplastycznionego tworzywa}

Możliwość powstania i widoczności śladów łączenia się strumieni tworzywa inaczej nazwanej linią zgrzewu (ang. Weld Line) opisują narzędzia symulacji Moldex: „Weld Line Meeting Angle” oraz „Weld Line Temperature”.

Narzędzie „Weld Line Meeting Angle” pokazuje jaki jest kąt pod którym czoła strug tworzywa spotykają się. Jeśli czoła tych strug zderzają się pod kątem mniejszym niż $135^{\circ}$ wzrasta prawdopodobieństwo uwidocznienia się linii zgrzewu na wyprasce. Im kąt większy od $135^{\circ}$ tym bardziej prawdopodobne, że linia nie powstanie. Jak widać na rysunku 3, na skali kolorem czerwonym oznaczono miejsca gdzie strugi cieczy łączą się pod kątem większym niż $135^{\circ}$ - tam też linia łączenia nie powinna być widoczna.

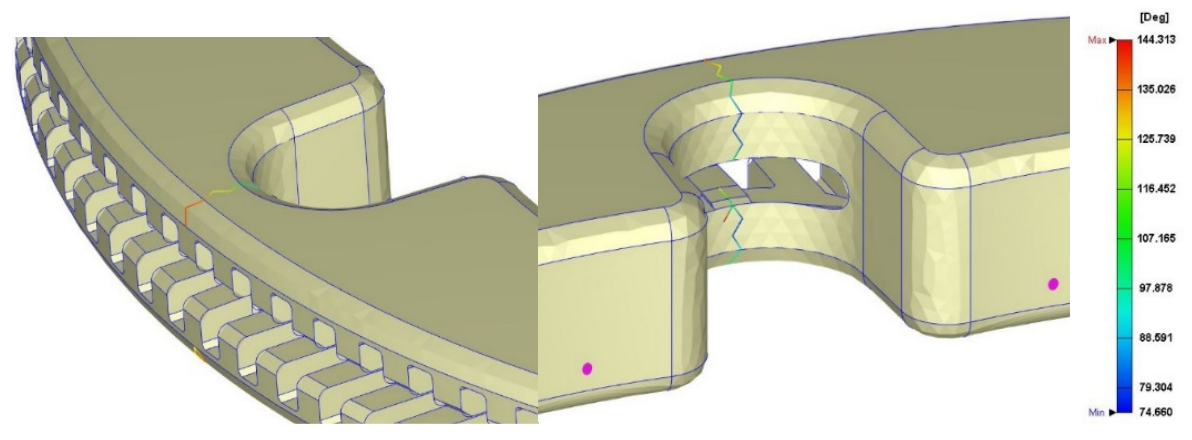

Rysunek 3. Weld Line Meeting Angle

Jak zostało to pokazane na zdjęciach (rys.4) wyniki symulacji pokrywają się z wynikami oględzin wyprasek.

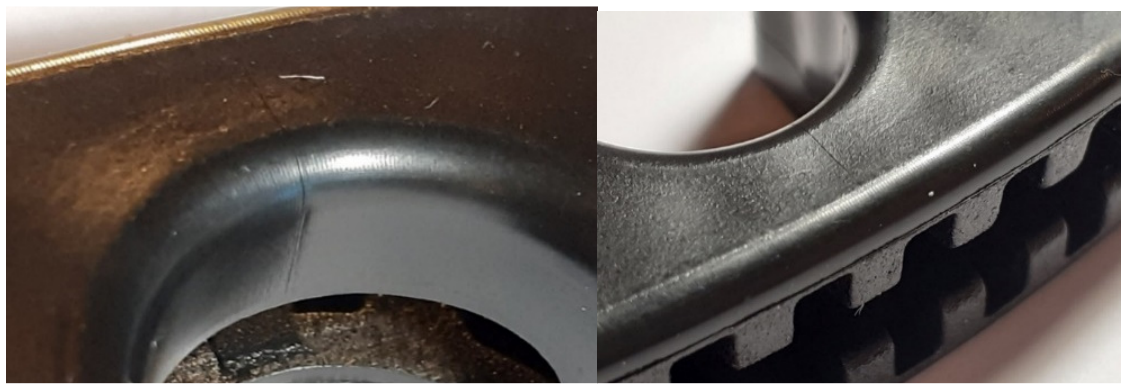

Rysunek 4. Linia łączenia strumieni tworzywa w rzeczysistej wyprasce

Narzedzie Weld Line Temperature określa rozkład temperatury w obszarach gdzie strugi tworzywa łączą się. Zwiększenie temperatury w potencjalnych liniach zgrzewu może ograniczyć ich uwidocznienie, jednak zbyt intensywne zwiększanie temperatury może powodować wypaczenia wypraski.

Warto zwrócić uwagę czy temperatura na linii zgrzewu (rys. 5), czyli w miejscu do którego tworzywo trafia niejako w ostatniej kolejności mieści się w zakresie 
temperatur w którym tworzywo jest plastyczne. Jeśli temperatura byłaby zbyt niska, w najlepszym wypadku wypraska będzie w tym miejscu znacznie osłabiona, w najgorszym - opuści formę wtryskową w dwóch lub więcej (zależnie od ilości punktów wtrysku) częściach.

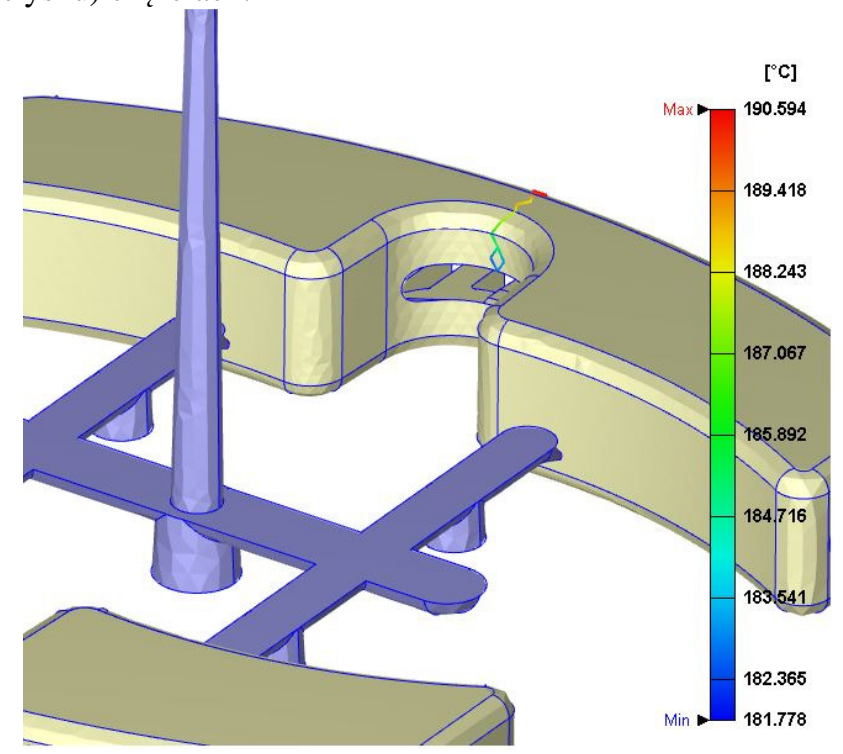

Rysunek 5. Weld Line Temperature

Aby sprawdzić wytrzymałość detalu w najsłabszym jego miejscu wykonano test zginania. Zniszczono kilka wyprasek (rys.6) i określono subiektywnie, że dla jej przewidzianego zastosowania (rączka do wiadra budowlanego) wytrzymałość na zginanie jest wystarczająca.

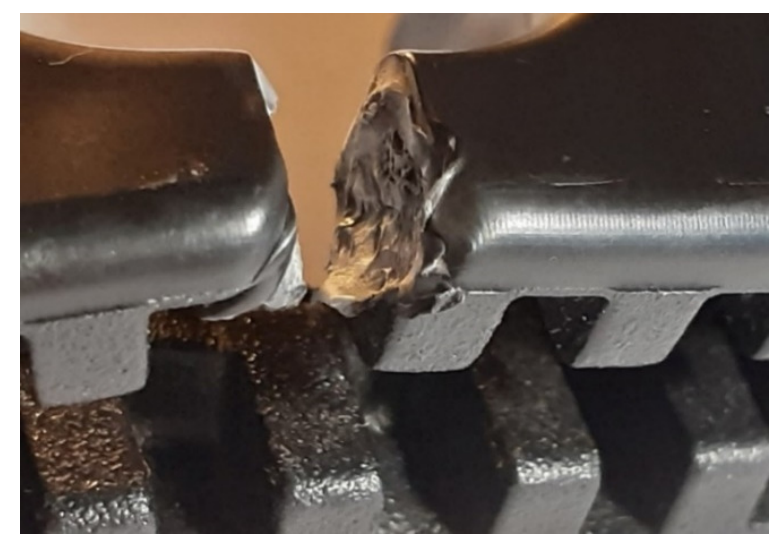

Rysunek 6. Zniszczona wypraska

\subsection{Zapadnięcia $w$ wyprasce}

Zapadnięcia są widoczne jako wgłębienia w powierzchni wypraski. Występują głównie w obszarach gwałtownego zwiększenia grubości ścianek detalu - ich 
pojawienie się na stronie przeciwnej do żebra jest bardzo typowe. Główną przyczyną powstawania tej wady jest niedostateczne upakowanie tworzywa w formie wtryskowej tj. zbyt krótki czas trwania fazy docisku po wtrysku i zbyt wolne krzepnięcie.

W obszarach wypraski, gdzie ścianki są grubsze, a co za tym idzie objętość tworzywa jest większa występuje większy skurcz objętościowy. Przy niedostatecznym upakowaniu tworzywa w gnieździe formującym powoduje to wciągnięcie zakrzepłej w pierwszej kolejności powierzchni wypraski w kierunku jej wnętrza. W przewidywaniu możliwości wystąpienia zapadnięć na powierzchni wypraski przydatne są wyniki symulacji: „Sink Mark Indicator” oraz „Sink Mark Displacement"

Sink Mark Indicator jest wskaźnikiem upakowania tworzywa w gnieździe formującym. Przy prawidłowym upakowaniu tworzywa wartość wskaźnika powinna wynosić 0. Jeśli wskaźnik jest dodatni - upakowanie tworzywa w gnieździe nie jest wystarczające, co może prowadzić do powstania zapadnięć. Jeśli wskaźnik jest ujemny - upakowanie jest zbyt duże. Wskaźnik Sink Mark Indicator dla analizowanej wypraski został przedstawiony na rysunku 6 (po lewej).

Narzędzie Sink Mark Displacement pokazuje występowanie i głębokość zapadnięć na powierzchni wypraski. (rysunek 7 (po prawej)). Wyniki symulacji zostały potwierdzone rzeczywistymi zapadnięciami na wyprodukowanej wyprasce, które zostały przedstawione na rysunku 8.

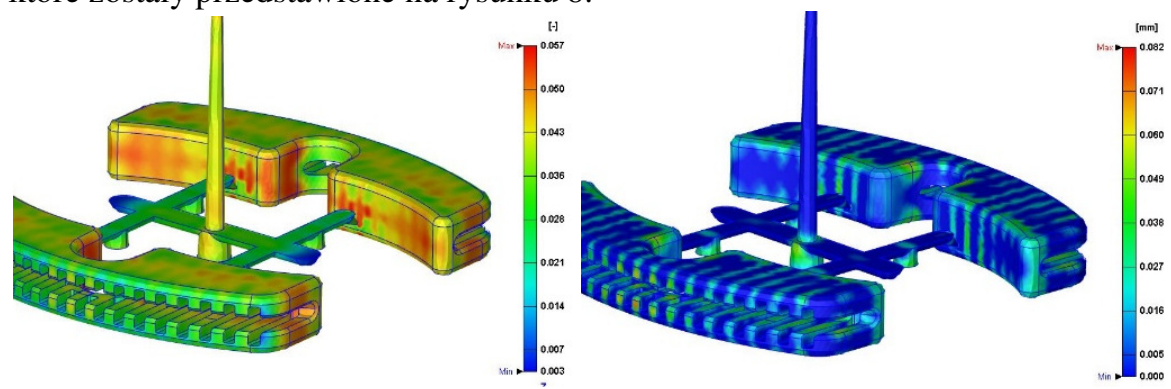

Rysunek 7. Sink Mark Indicator oraz Sink Mark Displacement

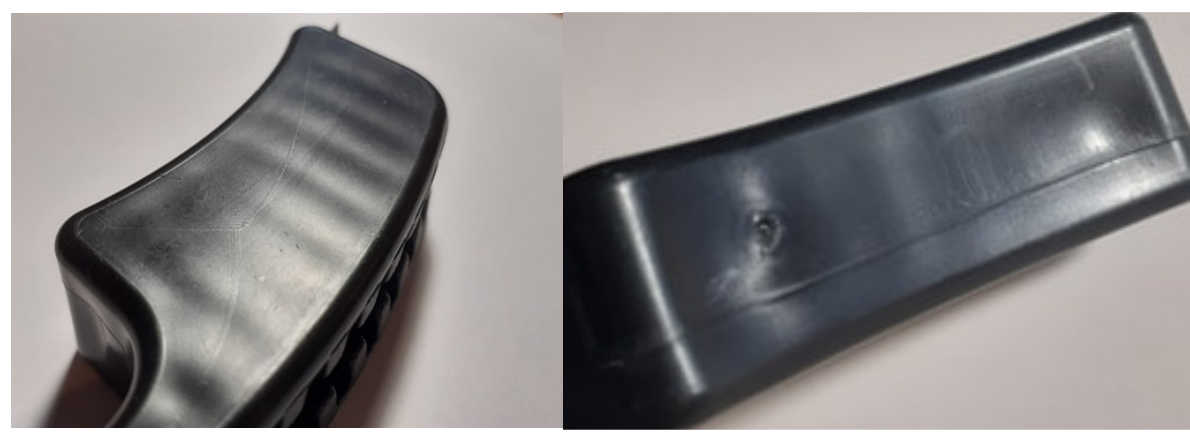

Rysunek 8 Zapadnięcia na powierzchni wypraski 


\subsection{Pęcherze powietrza}

Narzędzie „Air Trap” wskazuje lokalizacje, w których mogły powstać pęcherze powietrzne. Wada ta spowodowana jest zamykaniem gazu przez zbiegające się fronty uplastycznionego tworzywa.

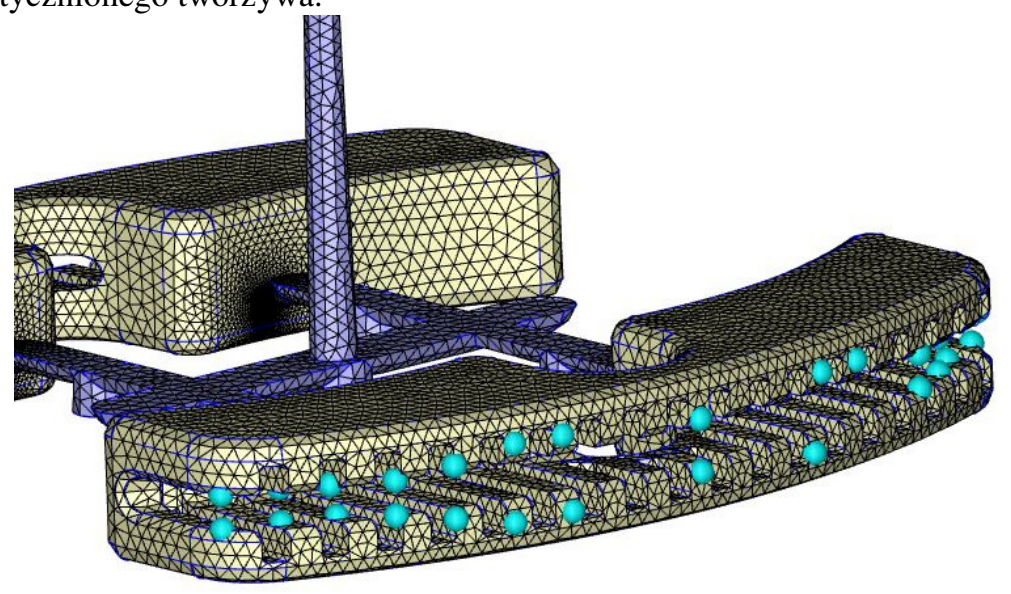

Rysunek 9 Air Traps

Wyniki z programu MOLDEX 3D wykazały, że pęcherze powietrza mogą utworzyć się w użebrowaniach, konkretnie - w obszarach które są wypełniane przez tworzywo w ostatniej kolejności (rys. 9). Są to miejsca nieistotne pod kątem wpływu tych wad na wytrzymałość wypraski, poza jednym - w przewężeniu detalu. Jak jednak wcześniej stwierdzono wytrzymałość uchwytu jest dostateczna. Na rysunku 10 przedstawiono pęcherze powietrza widoczne na przełomie detalu. Oprócz tego dokonano cięć wypraski $\mathrm{w}$ poprzek użebrowania w celu wykazania obecności pęcherzy powietrza w detalu.

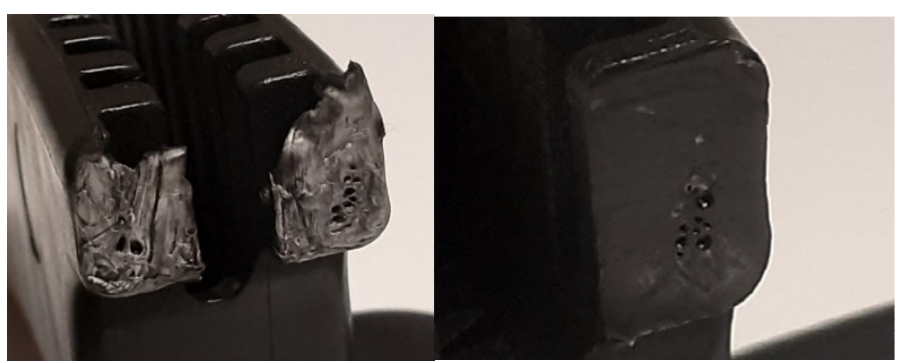

Rysunek 10 Pęcherze powietrza widoczne w przełomie i przekroju próbki

\subsection{Wypaczenia i deformacje wypraski}

W momencie wtrysku tworzywa do gniazda formującego, kształt wypraski odpowiada kształtowi gniazda. W miarę czasu trwania procesu wtrysku, docisku, chłodzenia i na końcu usunięcia wypraski z formy wtryskowej temperatura tworzywa spada aż do wyrównania się z temperaturą otoczenia. 
W tym czasie dochodzi do skrócenia pewnych wymiarów, deformacji kątów między ściankami wypraski, może nastąpić jej skręcenie lub pofałdowanie powierzchni. Proces ten związany jest $\mathrm{z}$ różnymi tendencjami do skurczu tworzywa w różnych obszarach wypraski, co wynika z różnego stopnia upakowania tworzywa $\mathrm{w}$ tych obszarach oraz $\mathrm{w}$ różnicach $\mathrm{w}$ szybkości stygnięcia wypraski, co $\mathrm{z}$ kolei związane jest z różnicami w grubości ścianek wypraski.

Oprogramowanie MOLDEX 3D pozwala na wyeksportowanie modeli zdeformowanych wyprasek $w$ formacie STEP. Tak wyeksportowane modele zaimportowano do oprogramowania SOLIDWORKS gdzie dokonano pomiarów modelu. Wyniki pomiaru głównych wymiarów liniowych pokazano na rysunku 11.

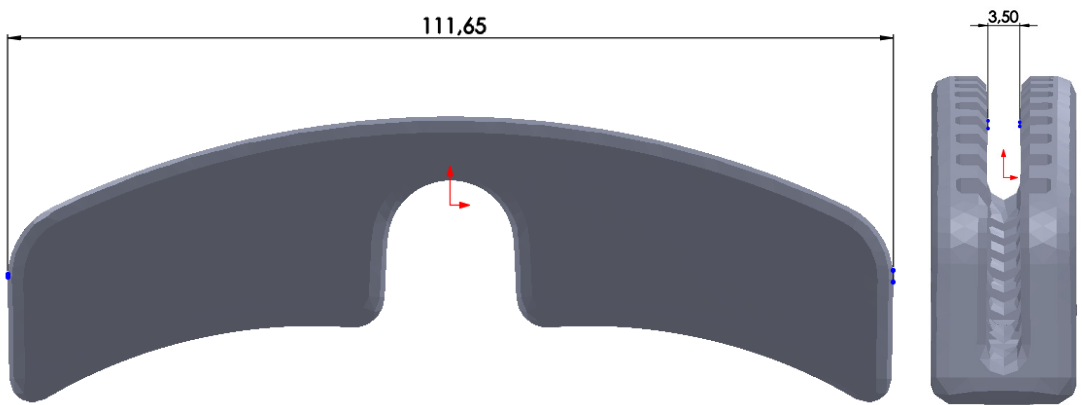

Rys. 11 Dtugość wypraski i szerokość rowka po odksztatceniu

Pomiar rzeczywistych wyprasek wykonano suwmiarką elektroniczną o dokładności $\pm 0,03 \mathrm{~mm}$ i rozdzielczości $\pm 0,01 \mathrm{~mm}$. Wyniki pomiarów w zakresie dokładności przyrządu odpowiadają wynikom pomiaru w środowisku SOLIDWORKS. Na rysunku 12 przedstawiono badaną wypraskę zamocowaną na pręcie uchwytu wiadra budowalnego.

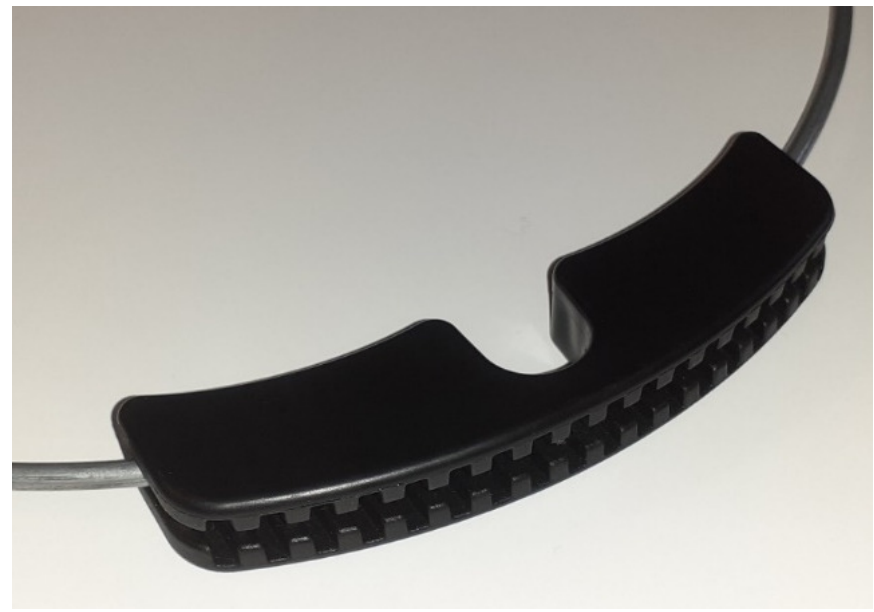

Rysunek 12 Wypraska zamontowana na pręcie (uchwyt wiadra budowlanego) 


\section{Podsumowanie i wnioski}

Z uzyskanych wyników symulacji (rysunek 8) wynika, że w najbardziej odległych od punktu wtrysku miejscach wypraski występują pęcherze powietrzne. Potwierdzono to w rzeczywistości przez wykonanie przełomu i przekrojów wypraski, (rysunek 10).

Widoczność linii łączenia (rysunek 3) jest konsekwencją kąta występującego między łączącymi się strugami uplastycznionego tworzywa. Jest on pokazany przez narzędzie Weld Line Meeting Angle. Wynik ten został potwierdzony na rzeczywistej wyprasce. Wada ta jest trudna a wręcz niemożliwa do uniknięcia przy zastosowaniu większej ilości punktów wtrysku w jednej wyprasce. W tym przypadku nie wpływa ona na własności użytkowe wypraski, a ze względu na jej małą widoczność także na równie ważny aspekt estetyczny gotowego produktu.

Aby sprawdzić, czy pęcherze powietrzne pojawiające się w przewężeniu wypraski wraz z linią łączenia nie wpływają na własności wytrzymałościowe wypraski dokonano przełomu kilku próbek. Wytrzymałość okazała się wystarczająca dla przewidzianego zastosowania produktu. Potwierdza to również wynik Weld Line Temperature, wkazujący na to, że czoła łączących się strumieni tworzywa miały temperaturę w zakresie plastyczności tworzywa.

Wadą technologiczną procesu wtrysku tworzywa są zapadnięcia widoczne na rysunku 8. Mogą one być spowodowane zbyt małym ciśnieniem drugiej fazy wtrysku - gdy plastyczne jeszcze tworzywo kurczy się w trakcie stygnięcia, ciśnienie to ma za zadanie dopełnić gniazdo formujące i zapobiec dalszemu skurczowi tworzywa. Ciśnienie to jest wyższe od ciśnienia wtrysku podczas pierwszego wypełniania gniazda i jest utrzymywane do momentu zastygnięcia tworzywa w kanale wlewowym. Wyniki symulacji z wykorzystaniem narzędzi Sink Mark Indicator oraz Sink Mark Displacement programu Moldex zostały potwierdzone przez widoczne zapadnięcia na powierzchni wyprasek (rysunek 8).

Jak wykazano w niniejszej pracy oprogramowanie Moldex pozwala zweryfikować wstępnie poprawność kształtu gniazda formującego oraz możliwości wykonania dobrej jakości detalu przy pomocy technologii wtrysku. Przed końcową obróbką cieplno - chemiczną części formujących i oddaniu formy do użytku należy jednak bezwzględnie przeprowadzić jej próby na wtryskarce, ponieważ. Program nie jest w stanie przewidzieć ewentualnych błędów popełnionych podczas produkcji formy wtryskowej.

\section{LITERATURA}

1. FRYNKIEL D., ZAWISTOWSKI H.: Konstrukcja form wtryskowych, Wydawnictwa Naukowo-Techniczne, Warszawa 1973.

2. Serwis internetowy: http://www.tworzywa.pwr.wroc.pl/pl/dydaktyka/definicja 
3. SIKORA R: Przetwórstwo tworzyw wielkocząsteczkowych, Wydawnictwo Edukacyjne Zofii Dobkowskiej, Warszawa 1993.

4. Serwis internetowy: http://www.tworzywa.pwr.wroc.pl/pl/dydaktyka/forma-wtryskowa

5. Serwis internetowy: http://www.tworzywa.pwr.wroc.pl/sites/default/files/plik_do_pobrania/formy_wtr yskowe.pdf

6. Serwis internetowy: http://support.moldex3d.com/r17/en/4-1-2-3_weldline.html

7. Serwis internetowy: http://support.moldex3d.com/r17/en/4-1-3-1_sinkmarkdisplacement.html

8. Serwis internetowy: http://support.moldex3d.com/r17/en/4-1-3-2_sinkmarkindicator.html

9. Serwis internetowy: http://support.moldex3d.com/r17/en/4-1-2-2_airtrap.html 